The cause of the hypoalbuminaemia remains obscure. In view of the abnormalities of absorption that were found it is tempting to suggest that an enteropathy, perhaps of the proteinloosing type, was responsible; unfortunately, radioalbumin studies and the polyvidone test were not carried out. It is, however, possible that this case represents only an exaggeration

\begin{tabular}{|c|c|c|c|c|c|}
\hline & $23 / 11 / 62$ & $10 / 12 / 62$ & $27 / 12 / 62$ & $22 / 2 / 63$ & $27 / 10 / 63$ \\
\hline 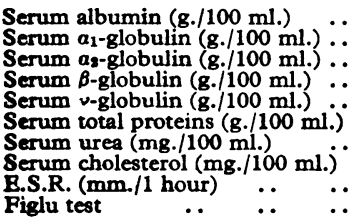 & $\begin{array}{c}\text { Low } \\
\text { Raised } \\
\\
6 \cdot 6 \\
53 \\
200 \\
43\end{array}$ & $\begin{array}{r}2 \cdot 0 \\
0 \cdot 3 \\
1 \cdot 0 \\
0 \cdot 7 \\
0.9 \\
4 \cdot 9 \\
44 \\
160 \\
29\end{array}$ & $\begin{array}{l}3 \cdot 3 \\
0.5 \\
1.3 \\
0.8 \\
0.9 \\
6.8 \\
44 \\
\\
\text { Pos. }\end{array}$ & $\begin{array}{l}3.6 \\
0.3 \\
0.9 \\
0.9 \\
1.2 \\
6.9\end{array}$ & $\begin{array}{l}3 \cdot 4 \\
0 \cdot 3 \\
0 \cdot 9 \\
0 \cdot 8 \\
1 \cdot 1 \\
6 \cdot 5 \\
34 \\
255 \\
15 \\
\text { Neg. }\end{array}$ \\
\hline
\end{tabular}

\section{Hydatid Disease of the Spine}

\section{Brit. med. F., 1965, 1, 633}

Man occasionally replaces domestic animals as the intermediate host in the life-cycle of the cestode Echinococcus granulosus. The resulting hydatid cysts usually develop in the liver and less frequently in the lungs; if the embryos pass the pulmonary filter cyst-formation may occur anywhere in the body. Although of great pathological interest, hydatid disease is not often encountered in clinical practice in Britain, and cases presenting as bone tumours are very rare.

\section{CASE REPORT}

An engineer aged 61 had suffered from low back pain of varying severity for 14 years. The pain occasionally radiated into the lateral aspect of the left thigh.

Examination showed him to be a heavily built man with an obese abdomen. All movements in the lumbar spine were limited, but

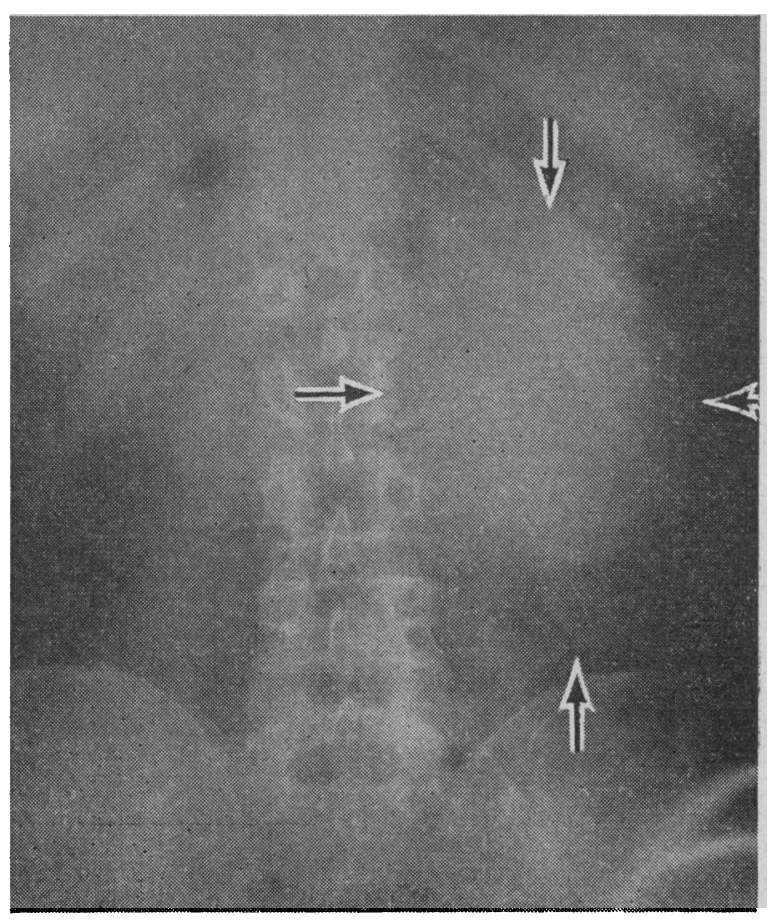

of the common mild reduction in serum albumin that occurs in hyperthyroidism.

I am grateful to Dr. G. E. Hosking and Dr. Aubrey Leatham for their encouragement and advice and for permission to publish the case report.

Whittington Hospital, London.

$$
\text { G. PinCherLe, M.B., M.R.C.P., }
$$

\section{REFERENCES}

Chapman, E. M., and Maloof, F. (1956). New Engl. f. Med., 254, 1. Ivy, H. K. (1963). Arch. intern. Med., 111, 607.

Lewis, L. A., and McCullagh, E. P. (1944). Amer. F. med. Sci., 208, 727. Nikkilä, E. A., and Pitkänen, E. (1959). Acta endocr. (Kbh.), 31, 573. Rothschild, M. A., Bauman, A., Yalow, R. S., and Berson, S. A. (1957). 7. clin. Invest., 36, 422 .

Shirer, J. W. (1932). Trans. Amer. Ass. Study Goitre, p. 89. there was no local tenderness, and the reflexes, muscular power, and sensation in the lower limbs were normal.

An $x$-ray film (see Fig.) revealed a large rounded shadow in the left lumbar region and apparent erosion of the left transverse process and adjacent part of the body of the second lumbar vertebra. It was at first thought to be a renal tumour, but an intravenous pyelogram showed the kidney to be displaced above the mass.

The swelling was explored through a left lumbar incision and was found to be a large tense cyst, adherent to the spine and eroding it. In dissecting the cyst from the vertebrae it was opened and was found to contain numerous daughter cysts, all of which were evacuated. The cyst wall was also excised. The appearance was characteristic of hydatid disease, and subsequent pathological examination of the specimen confirmed the presence of scolices. Despite the escape of fluid into the retroperitoneal tissues no manifestations of anaphylaxis appeared. Post-operatively, some wound discharge developed which yielded a growth of staphylococci; despite antibiotic therapy the resulting sinus took three months to heal.

\section{Comment}

According to Dew (1928) hydatid disease may begin in the bodies, pedicles, or laminae of the vertebrae and may remain confined to the bone for many years before extraosseous spread occurs. Root pain is common, though not usually severe, but cord pressure is slow to develop. Mills (1956), however, was able to collect 18 cases of paraplegia due to hydatid disease in British reports. In the Australian and New Zealand cases collected by Barnett (1945) about $2 \%$ of patients with hydatid disease had bone cysts, and half of these, or $1 \%$ of cases, involved the vertebrae. Woodland (1949) found six cases of vertebral disease in the records of the Sydney hospitals.

All reports agree that the radiological appearances are very variable ; Bellini (1946) believes the absence of collapse of the vertebral bodies, the escape of the intervertebral disks, and the presence of eburnation to be the most characteristic findings. Although complete eradication of the disease when it arises in the spine is probably impracticable, surgical excision is the only treatment of any benefit and should be as radical as possible.

\section{J. D. MaLlOCH, M.B., F.R.C.S.ED., Orthopaedic Surgeon, Scunthorpe and Lincoln Hospitals.}

\section{REFERENCES}

Barnett, L. E. (1945). Aust. N.Z. 7. Surg., 15, 72. Bellini, M. A. (1946). Radiology, 47, 569.

Dew, H. R. (1928). Hydatid Disease, p. 380 . Australasian Medical Publishing Co., Sydney.

Mills, T. J. (1956). F. Bone ft Surg., 38B, 884.

Woodland, L. J. (1949). Med. F. Aust., 2, 904. 